
Reactivity Fuel Combined with Direct Injection of Low Reactivity Fuels

\author{
Yong Qian, Qiyan Zhou, Xiaole Wang, Lifeng Zhu, Xingcai Lu*
}

Key Lab. for Power Machinery and Engineering of M. O. E, Shanghai Jiao Tong University, 200240, Shanghai, P. R.

Abstract: This paper presents a preliminary experimental study on the combustion and emission characteristics of Dual Fuel Sequential Combustion (DFSC) mode, in which port fuel injection of n-heptane combined with in-cylinder, directly injected ethanol, n-butanol and n-amyl alcohol are used in a single-cylinder engine at fixed directly injection timing. The results show that the heat release can be divided mainly into three stages: low temperature reaction, high temperature reaction of $\mathrm{n}$-heptane and the directly injected fuel combustion stage. The amount of port injected n-heptane plays a key role in the maximum in-cylinder pressure (Pmax), maximum in-cylinder mass averaged temperature (Tmax) and the maximum pressure rise rate. For the high overall lower heating values (LHVs) per-cycle, the $\mathrm{CO}$ emissions decrease with the increase of the premixed ratio. By contrast, the $\mathrm{CO}$ emissions increase with the premixed ratio when the overall LHVs per-cycle are kept at medium and low levels. The NOx and soot emissions are all kept at low levels for the experimental conditions. In particular, the higher latent heat, lower cetane values and the shorter carbon chains associated with ethanol lead to lower NOx and soot emissions than those of n-butanol and n-amyl alcohol. When directly injection of n-butanol and at low loads, with optimized premixed ratio, the indicated thermal efficiency can be higher than $46 \%$ meanwhile maintaining low emissions.

Key words: DFSC, n-heptane, ethanol, n-butanol, n-amyl alcohol, combustion and emissions 


\section{Introduction}

To address global energy problems and increasingly stringent emission regulations, biomass-based alternative fuels and new combustion modes are being widely developed [1, 2]. As alternative fuels, biomass-based fuels, which are commonly known as biofuels, possess many advantages over fossil fuels [3]. First, biofuels are easily available from common biomass sources. Second, the application of biofuels enables carbon circulation between the air and fuel, meaning problems such as greenhouse gas emissions and energy shortages can be solved together. Third, most biofuels, such as biodiesel and ethanol, have suitable physicochemical properties that permit effective combustion in internal combustion engines with or without minor modifications.

Ethanol is the only large-scale renewable fuel used currently $[4,5,6,7]$. Because the physical and chemical properties of ethanol are similar to that of gasoline, ethanol is added to gasoline in the United States, Canada, China and many other countries. A large number of studies have focused on the application of gasoline mixed with ethanol in a spark ignition (SI) engine $[8,9,10]$. Meanwhile, to realize the high efficiency of ethanol, and to find a solution to the problem of high NOx and soot emissions from traditional diesel engines, many scholars have studied using ethanol in a diesel engine [11, 12, 13]. He et al. [14] studied the mixing proportion of ethanol in diesel fuel blends and noted that as the proportion of ethanol mixed with diesel increases, the density, cetane number, kinematic viscosity, higher heating value and aromatic fractions of the blends decrease. Ignition improvement is needed to enhance the cetane number. Lu et al. [15] studied the combustion of diesel/ethanol blends and found that the combustion efficiency can be improved. For higher ethanol blending ratios, NOx and soot amounts decrease, whereas CO emissions increase. Li et al. studied the combustion and emissions characteristics of diesel/ethanol blends with 5\%, $10 \%, 15 \%$, and $20 \%$ ethanol/diesel ratio blends [16]. They found that the brake specific fuel consumption and brake thermal efficiency increased with the ethanol content for the overall operating conditions. 
under certain conditions, can also decrease NOx emissions [21, 22]. However, this decline has not achieved a breakthrough, and NOx emissions are still at high levels [23, 24]. In addition, because ethanol and diesel oil is difficult to stabilize, additives or solvents are required to make diesel/ethanol blends fuel stable miscible [25] However, diesel/ethanol blends have not yet gone into commercial applications or large scale production. attention [26, 27]. Szwaja et al [28] studied the combustion characteristics of $n$-butanol with an SI engine and found that the optimal ignition timing and antiknock properties of butanol are similar to gasoline with an octane number of approximately 87. Gu et al. [29] researched the effects of EGR on the emissions from n-butanol/gasoline blends in a gasoline engine. Studies show that when using an n-butanol/gasoline mixture, the HC, CO and NOx emissions can be reduced. EGR helps to reduce NOx emissions when using n-butanol/gasoline blends. Rakopoulos et al. [30] studied the combustion properties of $n$-butanol/diesel blends in a diesel engine. Their study found that mixing butanol into the blend can effectively reduce soot emissions and slightly decrease NOx emissions. Yao et al. [31] studied the effect of n-butanol as a diesel additive on engine performance and emissions for a heavy duty diesel engine. They found that while the NOx emissions are roughly the same, n-butanol can effectively improve the soot and CO emissions. Doğan et al. [32] studied the effects of n-butanol/diesel blends on engine performance and emissions and found that as the volume percentage of butanol increases, the soot, $\mathrm{CO}$ and NOx emissions decrease. However, the $\mathrm{HC}$ emissions increase. Rakopoulos et al. [33] studied the effects of $n$-butanol/diesel blends on engine performance and emissions in a high-speed diesel engine. Their results showed that as the volume percentage of n-butanol increased, the soot and $\mathrm{CO}$ emissions decreased gradually and that NOx emissions decreased slightly. However, HC emissions increased with the volume percentage of butanol. 
researched. In recent years, many scholars have performed studies on the homogeneous charge compression ignition (HCCI) combustion mode. These studies have produced a series of achievements, but for the existing technical conditions and control system, the full load range and variable operating conditions for HCCI combustion are still very difficult to control $[34,35]$. To achieve high efficiency and low emissions for different operating conditions, reactivity controlled compression ignition (RCCI) combustion mode is proposed [36, 37]. The internal combustion is well controlled by high EGR ratios and two stage fuel injection strategies [38, 39]. Recently, Lu et al proposed a dual fuel sequential compression combustion (DFSC) mode [40, 41]. DFSC introduces a well-mixed, lean fuel/air mixture into the cylinder by injecting a high cetane number fuel at the intake port, followed by the direct injection of a high-octane number fuel near top dead center (TDC).

In the DFSC mode, the port injected fuel, which has a high cetane value, burns first and combusts in the HCCI low temperature combustion mode. Meanwhile, the combustion of high cetane value fuels provides a suitable temperature and releases a large number of active radicals, which is beneficial to the combustion of directly injected fuels. In addition, the lower cetane value of direct injected fuel results in a delayed burn, which is beneficial to the mixing of the directly injected fuel. Furthermore, a direct injection fuel gasification process may lead to temperature drops in the cylinder, which effectively inhibits the generation of NOx.

Based on these reasons and considering the alcohol fuel properties, which generally include a high latent heat, high fuel oxygen content, and a low cetane value, an experimental study was conducted on the combustion and emissions characteristics of DFSC in a single-cylinder engine applying port injection of n-heptane combined with in-cylinder direct injection of ethanol, n-butanol and n-amyl alcohol, respectively. The combustion characteristics and emission properties are analyzed in detail.

\section{Experimental setup}

\subsection{Engine and instrumentation}


The experiments were performed on a modified single-cylinder, direct-injection, 4-stroke, water-cooled, injector for this system was mounted approximately $0.45 \mathrm{~m}$ upstream from the intake valve, with an injection pressure of 5 bar and port fuel injection timing of $340^{\circ} \mathrm{CA}$ BTDC. A direct injector (DI) with a cone angle of $154^{\circ}$ was used to inject different alcohols directly into the cylinder. The DI timing can be held constant by maintaining the fuel supply advance angle at $25^{\circ} \mathrm{CA}$ BTDC.

The in-cylinder gas pressure was measured using a pressure transducer (Kistler mode 6125B). The charge output from this transducer was converted to an amplified voltage using an amplifier (Kistler mode 5015A) and recorded at a resolution of $0.5^{\circ} \mathrm{CA}$. The exhaust gas components of the CO, UHC (unburned hydrocarbon), and NOx emissions were measured by a gas analyzer (AVL Digas 4000). The smoke opacity was measured by a smoke meter (AVL Dismoke 4000). The measured parameters and their accuracy are summarized in Table2. For all data presented, $0^{\circ} \mathrm{CA}$ is defined as TDC (top dead center) for the compression stroke. In consideration of the accuracy of g/kw-hr is highly relied on the accurate measurement of inlet air mass. For single cylinder engine, uneven intake flow leads to difficult accurate measurement of inlet air mass. In this work, ppm is used to discuss the gas emissions. purity n-heptane, ethanol, n-butanol and n-amyl alcohol are used. The properties of these fuels are listed in Table 3.

\subsection{Experimental procedure}



the combustion chamber and exhaust. Then, the direct injector is used to inject high octane fuel (in this study, the

112 high octane fuels are ethanol, n-butanol and n-amyl alcohol). Measurements are only taken after the $\mathrm{CO} 2$ content in

113 the exhaust flow has stabilized. In this experiment, the intake pressure is maintained at $1 \mathrm{~atm}$. The intake temperature

114 is controlled to be approximately $25^{\circ} \mathrm{C}$. The in-cylinder gas pressure was averaged over 100 consecutive cycles for 115 each operating point.

\section{Definition of the combustion parameters}

To investigate the combustion and emissions characteristics of DFSC fueled with n-heptane/alcohols fuels, several basic combustion parameters are defined. The ignition timing of the DFSC is defined as the crank angle position at which $10 \%$ of the fuel is burned, which is also referred to as CA10. CA50, which is another key parameter used to assess the combustion phasing, is defined as the crank angle position at which $50 \%$ of the fuel is burned. The combustion burn duration is defined as the crank angle interval between $10 \%$ and $90 \%$ of the mass fraction burned and overall lower heating values (LHVs) per-cycle, which are the sum of the energy of the premixed and directly injected fuels. In this paper, the premixed ratio (RP) is defined as the ratio of the energy of the premixed fuel $\mathrm{Q}_{\mathrm{PI}}$ to the total energy $\mathrm{Q}$. The premixed ratio can be calculated using the following formula:

$$
R P=\frac{Q_{P I}}{Q}=\frac{m_{P I} \times H_{u, P I}}{m_{P I} \times H_{u, P I}+m_{D I} \times H_{u, D I}},
$$

\section{$130 \quad$ 4. Experimental results and discussion}

$131 \quad 4.1$ Effects of premixed ratio on DFSC fueled with $n$-heptane/alcohols 
In DFSC mode, the in-cylinder combustible mixture is organized by port injection of high cetane number fuel combined with direct injection of high octane number fuel. For this condition, the premixed ratio directly determines the components and concentration stratification of the in-cylinder mixture, which has a significant impact on the combustion and emissions during the DFSC mode. Therefore, in this part, six premixed ratios $(0.38,0.46,0.52,0.63$, 0.71 and 0.82 ) are selected and the overall LHVs per-cycle is maintained at $1.01 \mathrm{~kJ} /$ cycle. The effects of the premixed ratio on the combustion and emission properties of n-heptane/alcohols fuels in DFSC mode were investigated.

Figure 2 shows the effects of the premixed ratio on the in-cylinder gas pressure and heat release rate curves for the DFSC mode using n-heptane/ethanol and n-heptane/n-butanol as fuels, respectively. From Fig. 2, it can be seen that under the DFSC combustion mode, the heat release rate curve exhibits a three-stage combustion progress, which includes low and high temperature reactions of n-heptane and the combustion of the directly injected alcohols. As the premixed ratio increases, the heat release rates for the low and high temperature reactions increase, while the peak value of the heat release rate for the directly injected fuel decreases.

From a further comparison of the heat release rate curves, it can be found that when the RP is 0.46 and 0.52 , the second stage of heat release for n-heptane/n-butanol occurs slightly earlier than for n-heptane/ethanol. This may due to the fact that ethanol's latent heat is higher than that of $n$-butanol. After the ethanol directly injected into the cylinder, the vaporized ethanol leads to a greater in-cylinder temperature decrease than for n-butanol. The combustion of n-heptane is similar to the HCCI mode, which is sensitive to variations in the in-cylinder temperature. In addition, the cetane number of ethanol is lower than that of n-butanol, the in-cylinder reactivity is lower when directly injected of ethanol. Meanwhile, due to lower LHV of ethanol, more ethanol should be injected into cylinder. The injection duration of ethanol would be longer which may lead ethanol difficult fully mixed with in-cylinder air. Finally these reasons lead to a slightly earlier heat release for the n-heptane/n-butanol than for the $n$-heptane/ethanol. When the premixed ratio is further increased to 0.63 and 0.71 , the quantity of the directly injected fuel is seen to decrease. The 
heat absorption by gasification decrease and the quantity of port injected n-heptane increases. The reaction activity of the in-cylinder n-heptane/air mixture is enhanced. The combustion is barely affected by the heat absorption from the direct injection fuel gasification. This causes when in high premixed ratio, the first and second stages of heat release of ethanol and butanol exhibit almost no difference.

Figure 3 shows the effects of the premixed ratio on the in-cylinder Pmax and Tmax of DFSC mode for different directly injected fuels. As seen in Fig. 3, as the RP increases, the maximum in-cylinder pressure and the maximum average temperature continuously increase. This is mainly because with increases to the premixed ratio, the combustion phase of the $n$-heptane is advanced and the concentration of $n$-heptane increases. More heat is released in the compression stroke, which increases the pressure and the cylinder temperature.

Figure 4 shows the relationship between the maximum pressure rise rates and the premixed ratio for different

164 directly injected alcohols. With the increase in RP, the maximum cylinder pressure rise rate increases gradually. This

165 is mainly because as the RP increases, the concentration of the port injected n-heptane increases. A higher concentration of n-heptane during compression leads to an increase in the maximum cylinder pressure rise rate. In addition, as the RP increases, the combustion phase is advanced. The peak value for the heat release rate curve is closer to TDC, which may also lead to an increase in the maximum pressure rise rate.

When the premixed ratio is less than 0.7 and for roughly the same RP, the difference in the maximum pressure

170 rise rates between different directly injected fuels is not obviously. This may be due to the maximum pressure rise 171 rate being achieved near TDC. For this condition, combustion is mainly achieved during the high temperature 172 reaction of the port injected n-heptane. The pressure rise rate for these crank angles are mainly determined by the 173 combustion of $n$-heptane, whereas the combustion of directly injected fuels have limited effects on the maximum 174 pressure rise rate, which finally leads to a slight difference in the maximum pressure rise rate between different the directly injected fuels. 
It is worth noting that the maximum pressure rise rate in the cylinder significantly increases when the premixed ratio is greater than 0.7 . This is because in-cylinder severe burning is caused by the high concentration of $n$-heptane.

178 For this condition, the in-cylinder pressure undulates violently, which leads to an irregular change in the maximum pressure rise rate when the premixed ratio is greater than 0.7 for the different directly injected fuels.

Figure 5 shows the effects of the premixed ratio on the emissions of DFSC mode for the different directly injected fuels. As seen in Fig. 5 (a), when the premixed ratio increases, the $\mathrm{CO}$ emissions first increase slightly and then decrease. The $\mathrm{CO}$ emissions are mainly determined by the degree of uniformity of the combustible mixture and the in-cylinder temperature. With the RP increases from 0.38 to 0.46 , the combustion phase of the directly injected fuel advances which is not advantageous for the mixing of fuel and air. This leads to an increase in CO emissions. With further increases to the premixed ratio, the in-cylinder temperature increases which helps to oxidize the CO, resulting in $\mathrm{CO}$ emissions decreasing. Figure 5 (b) shows an increase in the premixed ratio and the $\mathrm{HC}$ emissions increase gradually. This is primarily because as the RP increases, the accumulation of mixed gas in the cylindrical boundary layer increases. Thus, $\mathrm{HC}$ emissions tend to increase.

In Fig. 5 (c), the NOx emissions first increase and then decrease as the RP increases. The main reason for this is that as the premixed ratio increases, the in-cylinder combustion temperature gradually increases and part of the

191 directly injected fuel will participate in the high temperature reaction for $\mathrm{n}$-heptane combustion, which causes this part of the fuel to burn in a manner similar to diffusion combustion. For this condition, the combustion of a non-uniform mixture may lead to the formation of a local high temperature zone. This finally leads to an increase in the NOx emissions. With further increases to the premixed ratio, the quantity of directly injected fuel is continuously reduced. This may inhibit the non-uniform combustion of directly injected fuel, which causes the combustion mode to gradually convert to the HCCI mode and inhibits NOx formation. 

quantity of direct fuel injection decreases, meaning more fuel is injected into the cylinder using port injection. The fuel experience better mixing with the air and become more homogenous, resulting in a decrease in soot emissions. Additionally, when ethanol is directly injected, smoke emissions are maintained at a lower level. This is mainly due to the higher molecular weight of oxygen and the shorter carbon chains associated with the ethanol, which can inhibit the formation of soot precursors, lowering soot emissions than that of n-butanol and n-amyl alcohol. It is worth noting that for the range of premixed ratios greater than 0.35 , soot emissions are maintained at a low level.

\subsection{Effects of the overall LHVs per-cycle on the DFSC fueled using n-heptane/alcohols fuels}

The overall LHVs per-cycle are defined as the sum of LHVs per-cycle for the port and directly injected fuels. To a certain extent, the overall LHVs per-cycle provide a characterization of the engine load. To further investigate the combustion and emissions from the DFSC mode with direct injection of ethanol, n-butanol and n-amyl alcohol, respectively, under different loads, the premixed ratio is kept at 0.52 and six overall LHVs $(0.67,0.80,1.01,1.12$, 1.28 and $1.42 \mathrm{~kJ} /$ cycle) are selected pre-cycle. The effects of the overall LHVs per-cycle on the combustion and emission properties for different port injected alcohol-like fuels in the DFSC mode are discussed in detail.

Figure 6 shows the effects of the overall LHVs per-cycle on the in-cylinder gas pressure and the heat release rate of the DFSC mode for different directly injected fuels. From Fig. 6, it can be seen that as the overall LHVs per-cycle increase, the in-cylinder pressure curves continue to increase and the in-cylinder pressure curves for the n-heptane/n-butanol are higher than that of n-heptane/ethanol. However, this difference decreases as the overall LHVs per-cycle increase. This is mainly due to the higher concentration of n-heptane enhancing the high temperature reaction. directly injected fuel and the high temperature reactions for the $\mathrm{n}$-heptane increase. Some reasons for this may be that 
as the port injected n-heptane increases, the low-temperature and high-temperature reactions for the n-heptane are significantly improved as the overall LHVs per-cycle increase. Thus, the in-cylinder reaction activity is enhanced. Meanwhile, the quantity of the directly injected fuel also increases for the same RP. The high latent heat of the direct injected fuels reduces the in-cylinder gas temperature, which leads to an increase in the ignition delay for the direct injected fuels. For these two reasons, the combustion phase of the third reaction remains fairly constant when the overall LHVs per-cycle increases. However, the combustion phase for the first two stages is advanced because of a higher quantity of port injected n-heptane per-cycle. Consequently, the intervals between the combustions of the directly injected fuels and the high temperature reactions of the n-heptane are increased.

Figure 7 shows the effects of the overall LHVs per-cycle on the in-cylinder Pmax and Tmax for the DFSC mode for different directly injected fuels using the same premixed ratio. There is an increase in the overall LHVs per-cycle and the in-cylinder Pmax and Tmax increases. This trend is attributed to more fuel being injected into the cylinder per-cycle, especially for n-heptane, which leads to the advancement of the combustion phase and promotes in-cylinder combustion.

Figure 8 shows the effects of the LHVs per-cycle on the maximum pressure rise rate for the DFSC combustion mode. When the overall LHVs per-cycle are below $1.2 \mathrm{~kJ} /$ cycle, the maximum pressure rise rate for the DFSC combustion mode remains at a low level. However, when the overall LHVs per-cycle are greater than the $1.2 \mathrm{~kJ} / \mathrm{cycle}$, the maximum pressure rise rate increases sharply. This is because as the overall LHVs per-cycle increase, the heat release rate for port injected $n$-heptane increases and the concentration of $n$-heptane results in severe burning, which can lead to a higher maximum pressure rise rate. Comparing Figs. 4 and 8, it can be found that the in-cylinder maximum pressure rise rate always increases with the injection quantity for port fueled $n$-heptane. This trend shows

240 that the in-cylinder maximum pressure rise rate is mainly controlled by the high temperature reaction of n-heptane, meaning that an appropriate high temperature reaction rate for $n$-heptane and the combustion phase can optimize the 
maximum pressure rise rate.

Combining Figs. 7 and 8, it can be seen that no matter what the overall LHVs are, the differences between the

244 in-cylinder Pmax or the maximum pressure rise rates for different alcohol-based fuels are not obvious. The reason for

245 this is that Pmax and the maximum pressure rise rate occurs during the high temperature reaction for n-heptane,

246 which exhibits an HCCI-like combustion, resulting in the in-cylinder pressure rising rapidly. Otherwise, the alcohol

247 fuels directly injected into the cylinder mainly burn after TDC. At this time, the piston is already moving downward,

248 meaning that the in-cylinder pressure and the rise rate cannot be very high.

Figure 9 shows the effects of the overall LHVs per-cycle on the combustion phase and the burn duration for the

DFSC mode. As the overall LHVs per-cycle increase, CA10 and CA50 advance at first and then roughly remain

constant. However, the trends for CA90 are complicated. The advance in CA10 occur because as the overall LHVs

increase, the concentration of $n$-heptane increases. The in-cylinder reaction activity is enhanced, which may shorten the ignition delay. However, more fuel charges need to burn, which may delay the CA10. Therefore, CA10 advances at first and then remains constant. CA50 exhibits a similar trend as CA10. When the overall LHVs is lower, with an increases in the quantity of PI n-heptane, the peak value of heat release rate occurs earlier, at this time, the in-cylinder reaction activity is low and the high temperature flame of n-heptane has smaller influence on DI alcohol fuels, so that CA50 is not sensitive to the change of the overall LHVs. When the overall LHVs are higher, the advance of CA10 can promote CA50. Besides, the temperature of n-heptane high temperature combustion increases, more DI alcohol fuels burn at this stage, CA50 can be substantial advanced.

The trend for CA90 with the overall LHVs is more complex. First, as the overall LHVs increase, the quantity of the directly injected fuel increases, leading to a longer reaction time. This is the main reason for the delay in the occurrence of CA90. Second, the reaction temperature of the in-cylinder mixture increases as the overall LHVs increase, which can promote combustion. Third, the gasification of the directly injected fuel also has a great influence 
on CA90. In addition, CA10 also has great effect on CA90.

Figure 10 shows the effects of the overall LHVs per-cycle on the emissions for the DFSC combustion mode. In

266 Fig. 10 (a), as the overall LHVs increase, the CO emissions decrease. As the overall LHVs per-cycle increase, the

267 in-cylinder temperature increases, which benefit the $\mathrm{CO}$ conversion to $\mathrm{CO} 2$. In Fig. 10 (b), HC emissions remain at a

268 stable level. This is mainly due to an increase in the concentration of the premixed n-heptane as a greater fuel charge

269 is trapped in the crevices. However, the increase in the in-cylinder temperature can promote the oxidation of HC.

270 These two reasons lead to the $\mathrm{HC}$ emissions remaining at a stable level.

In Fig. 10 (c), NOx emissions increase initially and then decrease. At first, the increase in NOx is due to the rise

of the in-cylinder temperature. Then, as the overall LHVs increase, more alcohol fuel is injected into the cylinder,

which reduces the reaction temperature due to its high latent heat. In Fig. 10 (d), the soot emissions increase

274 gradually when the overall LHVs per-cycle increases. This is due to the increase in the quantity of the DI fuel and the and n-amyl alcohol.

4.3 The combined effects of the premixed ratio and the overall LHVs per-cycle on the combustion and emissions for the DFSC mode

For further analysis of the premixed ratio and the LHVs per-cycle on the combustion and emissions of DFSC mode fueled with n-heptane/alcohols, the experimental conditions for the premixed ratio are increased from 0.4 to 0.8 and LHVs per-cycle are increased to between 0.4 to $1.2 \mathrm{~kJ} /$ cycle for direct injection of ethanol and n-butanol, respectively. These are chosen for the plotting of contour maps for the main parameters of combustion and emissions.

Direct injection of ethanol is shown in red and n-butanol is shown in blue. 
Fig. 11 (a) and (b) show the combined effects of the premixed ratio and the LHVs per-cycle on CA10 and

287 CA50 for the DFSC mode, respectively. From Fig. 11 (a), it can be found that when the premixed ratio is constant, if

288 the LHVs per-cycle are increased, the CA10 continues to advance. When the LHVs per-cycle are constant, the CA10

289 increases with the increases of premixed ratio. The difference between directly injected ethanol and n-butanol is

290 smaller when the LHVs per-cycle are higher than that for the $1.6 \mathrm{~kJ} / \mathrm{cycle}$. The CA10 of n-butanol was significantly

291 more advanced than that of ethanol when the LHVs per-cycle are lower than $1.6 \mathrm{~kJ} / \mathrm{cycle}$. Fig. 11 (b) shows the

292 combined effects of the premixed ratio and LHVs per-cycle on the CA50 for the DFSC mode. The difference is

293 insignificant when both the LHVs per-cycle and the premixed ratio are high. For other conditions, the CA50 of the

294 directly injected n-butanol is advanced compared to that of ethanol.

Fig. 11 (c) shows the combined effects of the premixed ratio and the LHVs per-cycle on the combustion

296 duration for the DFSC mode. When the LHVs per-cycle is fixed, the combustion duration can be gradually shortened

297 by increasing the premixed ratio for $\mathrm{n}$-heptane/ethanol. However, for directly injected n-butanol, when the LHVs

298 per-cycle are higher than 0.6, the combustion duration is gradually shortened as the premixed ratio is increased.

299 When the LHVs per-cycle are lower than 0.6, combustion duration changes slightly as the premixed ratio is

300 increased. From a comparison of directly injected ethanol and n-butanol, it can be found that when the LHVs

301 per-cycle are higher than 0.6 and the premixed ratio is higher than 0.65 , there is not an obvious difference between

302 using ethanol and n-butanol. However, for other conditions, the combustion duration of the ethanol is longer than

303 that of n-butanol.

Figure 12 shows the combined effects of premixed ratio and LHVs per-cycle on the main gas emissions for the

305 DFSC mode. Fig. 12 shows that for different direct injection of alcohol-like fuels, there are several common features

306 in the gas emissions for the DFSC mode. The CO and NOx emissions decrease with the increase in the LHVs

307 per-cycle. Soot emissions reach a maximum at a low premixed ratio and high LHVs per-cycle. At approximately the 
same loads, the CO, NOx and soot emissions from the ethanol are a little higher than that for the n-butanol. The

higher molecular oxygen and the higher latent heat of the ethanol help to inhibit the emissions. In addition, it is worth noting that for direct injection of ethanol and butanol, soot and NOx emissions are maintained at a low level.

Fig. 13 shows the combined effects of the premixed ratio and the LHVs per-cycle on the indicated mean effective pressure (IMEP) and indicated thermal efficiency of DFSC mode. In figure 13 (a), it can be found that under current operating conditions, the loads can be reached in the range from 1 to 6 bar. When in high LHVs per-cycle and

314 with the increase of premixed ratio, the engine loads increase first and then decrease. When in high LHVs per-cycle,

315 with the increase of premixed ratio, the engine loads are decreased gradually. This is mainly determined by the 316 reaction characteristics of direct injected alcohols and in-cylinder reaction activity.

In figure 13 (b), for port injection of ethanol and n-butanol, when in low premixed ratio and in medium and low

318 LHVs per-cycle, the indicated thermal efficiency would be higher. Under this condition, the amount of port injected 319 n-heptane is suitable to control the combustion phase. It can also be found in figure 13 (b) that in most loads, when 320 directly injected of n-butanol, the indicated thermal efficiency would be higher than that of ethanol. The main reason 321 is that for n-butanol, which has higher cetane number and lower latent heat makes the CA50 earlier and the 322 combustion duration shorter. So that the indicated thermal efficiency would be higher.

\section{5. Conclusions}

An experimental study was conducted on the combustion and emissions characteristics of DFSC in a single-cylinder engine using port injection of n-heptane combined with in-cylinder direct injection of ethanol, n-butanol and n-amyl alcohol. The combustion parameters, main emissions and the heat release features are analyzed in detail. From this research, the following conclusions are reached: 
(1) The heat release may be divided into three stages, which are the low temperature and high temperature reaction of $\mathrm{n}$-heptane and the directly injected fuel combustion stage.

(2) The amount of port injected n-heptane plays a key role in Pmax, Tmax and the maximum pressure rise rate for the DFSC mode.

(3) When in the high overall LHVs per-cycle, the CO emissions decrease with the increase of the premixed ratio. By contrast, the $\mathrm{CO}$ emissions increase with the increase of premixed ratio when the overall LHVs per-cycle is in medium and low levels.

(4) NOx and soot emissions are kept at low levels for the current experimental conditions. The soot emissions reach a maximum value for a low premixed ratio and high overall LHVs per-cycle. In particular, the higher latent heat of vaporization, the lower cetane values and the shorter carbon chains associated with the ethanol lead to lower NOx and soot emissions than observed for n-butanol and n-amyl alcohol.

(5) Compared to ethanol, under the current conditions, when directly injection of n-butanol, the indicated thermal efficiency would be higher. This is mainly due to the higher cetane number, lower latent heat of n-butanol which lead to more suitable combustion phase. It is worth noting that current experiments are not optimized. For optimized direct injection pressure and timing, the indicated thermal efficiency of ethanol would be higher.

\section{Acknowledgments}

This work was supported by the National Science Foundation for Distinguished Young Scholars of China (Grant No.

\section{References}

350 1. Raheem, A., Azlina, W. W., Yap, Y. T., Danquah, M. K., \& Harun, R. (2015). Thermochemical conversion of microalgal biomass for biofuel production.Renewable and Sustainable Energy Reviews, 49, 990-999.

352 2. Lu X. C., Han D., \& Huang, Z. (2011). Fuel design and management for the control of advanced compression-ignition combustion 
modes. Progress in Energy and Combustion Science, 37(6), 741-783.

3. Qian Y., Zhu L. F., Wang Y., \& Lu, X.C. (2015). Recent progress in the development of biofuel 2, 5-dimethylfuran. Renewable and Sustainable Energy Reviews, 41, 633-646.

4. Duff, S. J., \& Murray, W. D. (1996). Bioconversion of forest products industry waste cellulosics to fuel ethanol: a review. Bioresource Technology, 55(1), 1-33.

5. Sun, Y., \& Cheng, J. (2002). Hydrolysis of lignocellulosic materials for ethanol production: a review. Bioresource technology, 83(1), 1-11.

6. Galbe, M., \& Zacchi, G. (2002). A review of the production of ethanol from softwood. Applied microbiology and biotechnology, 59(6), 618-628.

7. Hsieh, W. D., Chen, R. H., Wu, T. L., \& Lin, T. H. (2002). Engine performance and pollutant emission of an SI engine using ethanol-gasoline blended fuels. Atmospheric Environment, 36(3), 403-410.

8. Yüksel, F., \& Yüksel, B. (2004). The use of ethanol-gasoline blend as a fuel in an SI engine. Renewable energy, 29(7), 1181-1191.

9. Abdel - Rahman, A. A., \& Osman, M. M. (1997). Experimental investigation on varying the compression ratio of SI engine working under different ethanol-gasoline fuel blends. International Journal of Energy Research,21(1), 31-40.

10. Kiani, M. K. D., Ghobadian, B., Tavakoli, T., Nikbakht, A. M., \& Najafi, G. (2010). Application of artificial neural networks for the prediction of performance and exhaust emissions in SI engine using ethanol-gasoline blends. Energy, 35(1), 65-69.

11. Rakopoulos, D. C., Rakopoulos, C. D., Kakaras, E. C., \& Giakoumis, E. G. (2008). Effects of ethanol-diesel fuel blends on the performance and exhaust emissions of heavy duty DI diesel engine. Energy Conversion and Management, 49(11), 3155-3162.

12. Demirbas, A. (2009). Political, economic and environmental impacts of biofuels: A review. Applied Energy, 86, S108-S117.

13. Rakopoulos, C. D., Antonopoulos, K. A., \& Rakopoulos, D. C. (2007). Experimental heat release analysis and emissions of a HSDI diesel engine fueled with ethanol-diesel fuel blends. Energy, 32(10), 1791-1808.

14. He B. Q., Shuai S. J., Wang J. X., \& He H. (2003). The effect of ethanol blended diesel fuels on emissions from a diesel engine. Atmospheric Environment, 37(35), 4965-4971.

15. Lu X. C., Yang J. G, Zhang W. G., \& Huang, Z. (2004). Effect of cetane number improver on heat release rate and emissions of high speed diesel engine fueled with ethanol-diesel blend fuel. Fuel, 83(14), 2013-2020.

16. Li D. G., Zhen H., Lu X. C., Zhang W. G., \& Yang J. G. (2005). Physico-chemical properties of ethanol-diesel blend fuel and its effect on performance and emissions of diesel engines. Renewable energy, 30(6), 967-976.

17. Sayin C. Engine performance and exhaust gas emissions of methanol and ethanol-diesel blends. Fuel, 2010, 89(11): 3410-3415.

18. Rakopoulos, C. D., Antonopoulos, K. A., Rakopoulos, D. C., \& Hountalas, D. T. (2008). Multi-zone modeling of combustion and emissions formation in DI diesel engine operating on ethanol-diesel fuel blends. Energy conversion and management, 49(4), 625-643.

19. Giakoumis, E. G., Rakopoulos, C. D., Dimaratos, A. M., \& Rakopoulos, D. C. (2013). Exhaust emissions with ethanol or n-butanol diesel fuel blends during transient operation: a review. Renewable and Sustainable Energy Reviews, 17, 170-190.

20. Ajav, E. A., Singh, B., \& Bhattacharya, T. K. (1999). Experimental study of some performance parameters of a constant speed stationary diesel engine using ethanol-diesel blends as fuel. Biomass and Bioenergy, 17(4), 357-365.

21. Can, Ö., Celikten, I., \& Usta, N. (2004). Effects of ethanol addition on performance and emissions of a turbocharged indirect injection diesel engine running at different injection pressures. Energy Conversion and Management, 45(15), 2429-2440.

22. Kim, H., \& Choi, B. (2008). Effect of ethanol-diesel blend fuels on emission and particle size distribution in a common-rail direct injection diesel engine with warm-up catalytic converter. Renewable Energy, 33(10), 2222-2228.

23. Lu, X. C., Huang, Z., Zhang, W. G., \& Li, D. G. (2004). The influence of ethanol additives on the performance and combustion characteristics of diesel engines. Combustion Science and Technology, 176(8), 1309-1329.

24. Hulwan, D. B., \& Joshi, S. V. (2011). Performance, emission and combustion characteristic of a multicylinder DI diesel engine running on diesel-ethanol-biodiesel blends of high ethanol content. Applied Energy,88(12), 5042-5055.

25. Hansen, A. C., Zhang, Q., \& Lyne, P. W. (2005). Ethanol-diesel fuel blends-a review. Bioresource technology, 96(3), $277-285$.

26. Alasfour, F. N. (1997). Butanol-a single-cylinder engine study: availability analysis. Applied Thermal Engineering, 17(6), 537-549.

27. Rakopoulos, D. C., Rakopoulos, C. D., Giakoumis, E. G., Dimaratos, A. M., \& Kyritsis, D. C. (2010). Effects of butanol-diesel fuel blends 
on the performance and emissions of a high-speed DI diesel engine. Energy Conversion and Management, 51(10), 1989-1997.

28. Szwaja, S., \& Naber, J. D. (2010). Combustion of n-butanol in a spark-ignition IC engine. Fuel, 89(7), 1573-1582.

29. Gu, X., Huang, Z., Cai, J., Gong, J., Wu, X., \& Lee, C. F. (2012). Emission characteristics of a spark-ignition engine fuelled with

400 gasoline-n-butanol blends in combination with EGR. Fuel, 93, 611-617.

401 30. Rakopoulos, D. C., Rakopoulos, C. D., Hountalas, D. T., Kakaras, E. C., Giakoumis, E. G., \& Papagiannakis, R. G. (2010). Investigation of the performance and emissions of bus engine operating on butanol/diesel fuel blends. Fuel, 89(10), 2781-2790.

31. Yao, M., Wang, H., Zheng, Z., \& Yue, Y. (2010). Experimental study of n-butanol additive and multi-injection on HD diesel engine performance and emissions. Fuel, 89(9), 2191-2201.

32. Doğan O. The influence of $<\mathrm{i}>\mathrm{n}</ \mathrm{i}>$-butanol/diesel fuel blends utilization on a small diesel engine performance and emissions. Fuel, 2011, 90(7): 2467-2472.

33. Rakopoulos, D. C., Rakopoulos, C. D., Giakoumis, E. G., Dimaratos, A. M., \& Kyritsis, D. C. (2010). Effects of butanol-diesel fuel blends on the performance and emissions of a high-speed DI diesel engine. Energy Conversion and Management, 51(10), 1989-1997.

409 34. Lu, X. C., Hou, Y. C., Ji, L. B., Zu, L. L., \& Huang, Z. (2006). Heat release analysis on combustion and parametric study on emissions of HCCI engines fueled with 2-propanol/n-heptane blend fuels. Energy \& fuels, 20(5), 1870-1878.

35. Shibata, G., Oyama, K., Urushihara, T., \& Nakano, T. (2004). The effect of fuel properties on low and high temperature heat release and resulting performance of an HCCI engine. SAE Technical Paper 2004-01-0553.

36. Reitz, R. D., \& Duraisamy, G. (2015). Review of high efficiency and clean reactivity controlled compression ignition (RCCI) combustion in internal combustion engines. Progress in Energy and Combustion Science, 46, 12-71.

37. Qian, Y., Wang, X., Zhu, L., \& Lu, X. C. (2015). Experimental studies on combustion and emissions of RCCI (reactivity controlled compression ignition) with gasoline/n-heptane and ethanol/n-heptane as fuels. Energy, 88, 584-594.

38. Kokjohn, S. L., Hanson, R. M., Splitter, D. A., \& Reitz, R. D. (2011). Fuel reactivity controlled compression ignition (RCCI): a pathway to controlled high-efficiency clean combustion. International Journal of Engine Research,12(3), 209-226.

39. Kokjohn, S., Hanson, R., Splitter, D., Kaddatz, J., \& Reitz, R. D. (2011). Fuel reactivity controlled compression ignition (RCCI) combustion in light-and heavy-duty engines. SAE International Journal of Engines, 4(2011-01-0357), 360-374.

40. Lu, X. C., Zhou, XX., Ji, L. B., Yang, Z., Han, D., Chen, H., \& Huang, Z. (2013). Experimental studies on the dual-fuel sequential combustion and emission simulation. Energy, 51, 358-373. with n-Heptane/Gasoline-Like Fuels. SAE Technical Paper 2014-01-2682. 
Enabling Dual Fuel Sequential Combustion using Port Fuel Injection of High Reactivity Fuel Combined with Direct Injection of Low Reactivity Fuels

\author{
Yong Qian, Xiaole Wang, Lifeng Zhu, Xingcai Lu*
}

Key Lab. for Power Machinery and Engineering of M. O. E, Shanghai Jiao Tong University, 200240, Shanghai, P. R.

China

Table 1. Engine specifications

\begin{tabular}{|l|l|l|l|}
\hline Displaced volume & $0.792 \mathrm{~L}$ & Exhaust Valve Open & $114^{\circ} \mathrm{CA}$ ATDC \\
\hline Stroke & $105 \mathrm{~mm}$ & Exhaust Valve Close & $348^{\circ} \mathrm{CA} \mathrm{BTDC}$ \\
\hline Bore & $98 \mathrm{~mm}$ & Inlet Valve Open & $344^{\circ} \mathrm{CA}$ ATDC \\
\hline Compression ratio & $18.5: 1$ & Inlet Valve Close & $128^{\circ} \mathrm{CA}$ BTDC \\
\hline Number of Valves & 4 & Needle Open Pressure & $24 \mathrm{Mpa}$ \\
\hline
\end{tabular}

Corresponding author: E-mail address: lyuxc@sjtu.edu.cn. Tel.: +86-21-34206039; Fax: +86-21-34205949. 
Table 2. Accuracies of the measurements

\begin{tabular}{|l|l|l|l|}
\hline Measured parameters & Unit & Measurement range & Accuracy \\
\hline Engine speed & $\mathrm{r} / \mathrm{min}$ & $0-10,000$ & \pm 1 \\
\hline Engine torque & $\mathrm{Nm}$ & $0-200$ & \pm 0.1 \\
\hline Cylinder pressure & $\mathrm{MPa}$ & $0-25$ & \pm 0.0005 \\
\hline Intake pressure & $\mathrm{kPa}$ & $0-500$ & \pm 0.5 \\
\hline Intake air temperature & ${ }^{\circ} \mathrm{C}$ & $0-200$ & \pm 0.1 \\
\hline Exhaust gas temperature & ${ }^{\circ} \mathrm{C}$ & $0-800$ & \pm 1 \\
\hline Coolant temperature & ${ }^{\circ} \mathrm{C}$ & $0-150$ & \pm 0.1 \\
\hline Lubricant oil temperature & ${ }^{\circ} \mathrm{C}$ & $0-150$ & \pm 0.1 \\
\hline CO emissions & $\%$ & $0-4.0$ & \pm 0.01 \\
\hline HC emissions & $\mathrm{ppm}$ & $0-10,000$ & \pm 1 \\
\hline NOx emissions & $\mathrm{ppm}$ & $0-4000$ & \pm 1 \\
\hline Soot emissions & $\mathrm{m}-1$ & $0-99.99$ & $\pm 1 \%$ \\
\hline Fuel consumption & $\mathrm{kg} / \mathrm{h}$ & $0-10$ & $\pm 1 \%$ \\
\hline
\end{tabular}


Table 3. Fuel properties

\begin{tabular}{|l|l|l|l|l|}
\hline & N-heptane & Ethanol & N-butanol & N-amyl alcohol \\
\hline Molecular formula & n-C7H16 & C2H6O & n-C4H10O & n-C5H12O \\
\hline Molecular weight & 100.2 & 46 & 74.12 & 88 \\
\hline Density g/cm3 @ 20 ${ }^{\circ} \mathrm{C}$ & 0.682 & 0.746 & 0.8098 & 0.8114 \\
\hline Purity \% & $>97.33$ & $>99.9$ & $>99.5$ & $>99.5$ \\
\hline Lower heat value (MJ/kg) & 44.57 & 26.8 & 33.04 & 35.2 \\
\hline Latent heat (kJ/kg) & 316 & 862 & 584 & 427 \\
\hline Research octane number & 0 & 110 & 87 & - \\
\hline Cetane number & 56 & 8 & $\sim 25$ & - \\
\hline Carbon content \% (mass) & 84 & 52 & 65 & 68 \\
\hline Hydrogen content \% (mass) & 16 & 13 & 13 & 14 \\
\hline Oxygen content \% (mass) & 0 & 35 & 22 & 18 \\
\hline Stoichiometric ratio & 15.3 & 9 & 11.1 & 11.7 \\
\hline
\end{tabular}




\title{
Enabling Dual Fuel Sequential Combustion using Port Fuel Injection of High Reactivity Fuel Combined with Direct Injection of Low Reactivity Fuels
}

\author{
Yong Qian, Xiaole Wang, Lifeng Zhu, Xingcai Lu* \\ Key Lab. for Power Machinery and Engineering of M. O. E, Shanghai Jiao Tong University, 200240, Shanghai, P. R. \\ China
}

Fig. 1 Schematic of the engine and instrumentation setup

Fig. 2 Effects of the premixed ratio on the in-cylinder gas pressure and the heat release rate curves for the DFSC mode with directly injected fuels

Fig. 3 Effects of the premixed ratio on the in-cylinder Pmax and Tmax for the DFSC mode using directly injected fuels

Fig. 4 Effects of the premixed ratio on the maximum pressure rise rate during the DFSC mode with directly injected fuels

Fig. 5 Effects of the premixed ratio on the emissions of DFSC mode for different directly injected fuels

Fig. 6 Effects of the overall LHVs per-cycle on the in-cylinder gas pressure and heat release rate curves for the DFSC mode for different directly injected fuels

Fig. 7 Effects of the overall LHVs per-cycle on the in-cylinder Pmax and Tmax for the DFSC mode

Fig. 8 Effects of the overall LHVs per-cycle on the maximum pressure rise rate for the DFSC combustion mode

Fig. 9 Effects of the overall LHVs per-cycle on the combustion phase

Fig. 10 Effects of overall LHVs per-cycle on the emissions of DFSC combustion mode

Fig. 11 Combined effects of the premixed ratio and the LHVs per-cycle on the combustion parameters of the DFSC

Fig. 12 Combined effects of the premixed ratio and the LHVs per-cycle on the main gas emissions for the DFSC

Fig. 13 Combined effects of the premixed ratio and the LHVs per-cycle on the IMEP and indicated thermal efficiency of DFSC mode

Corresponding author: E-mail address: lyuxc@sjtu.edu.cn. Tel.: +86-21-34206039; Fax: +86-21-34205949. 


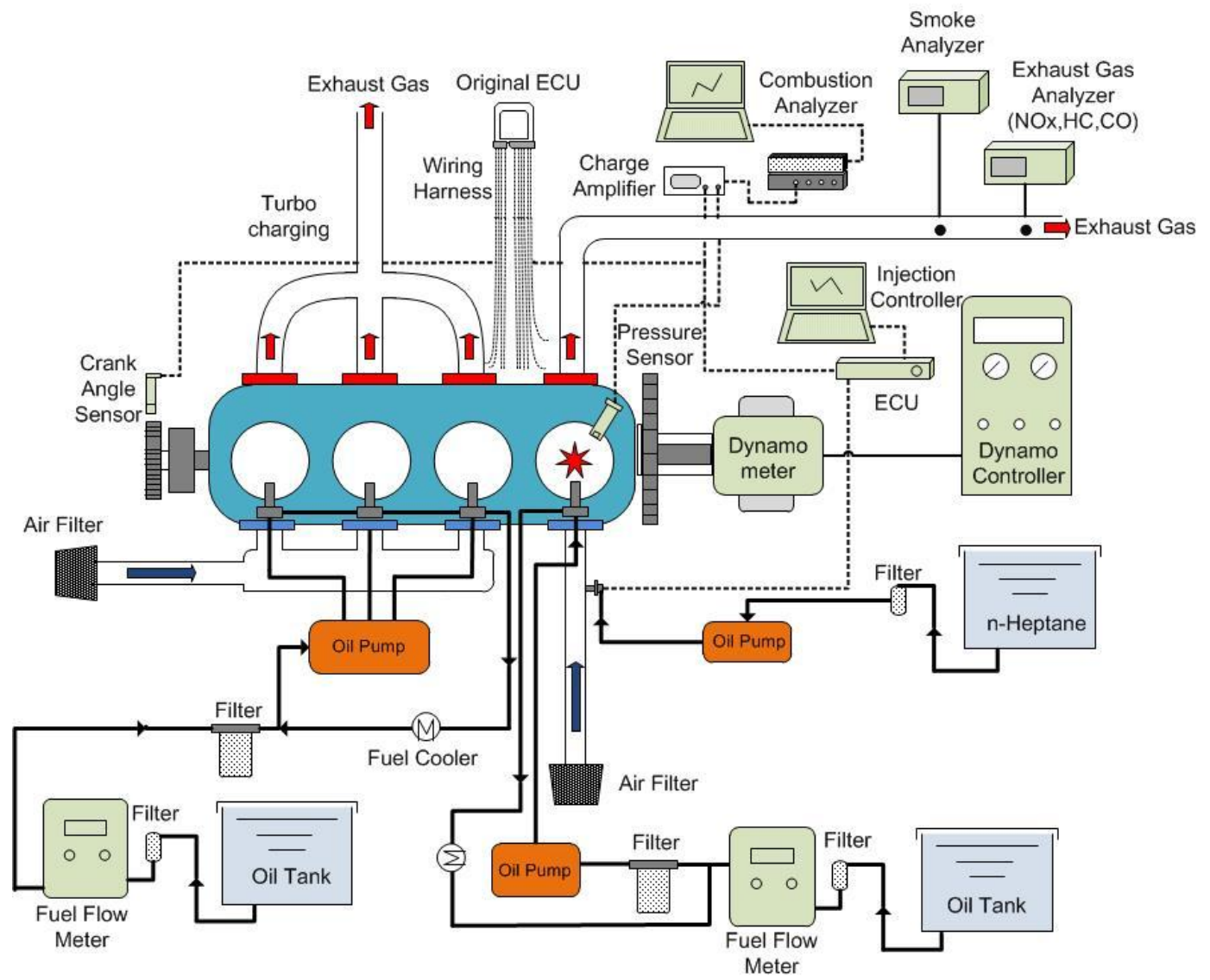

Fig. 1 Schematic of the engine and instrumentation setup 

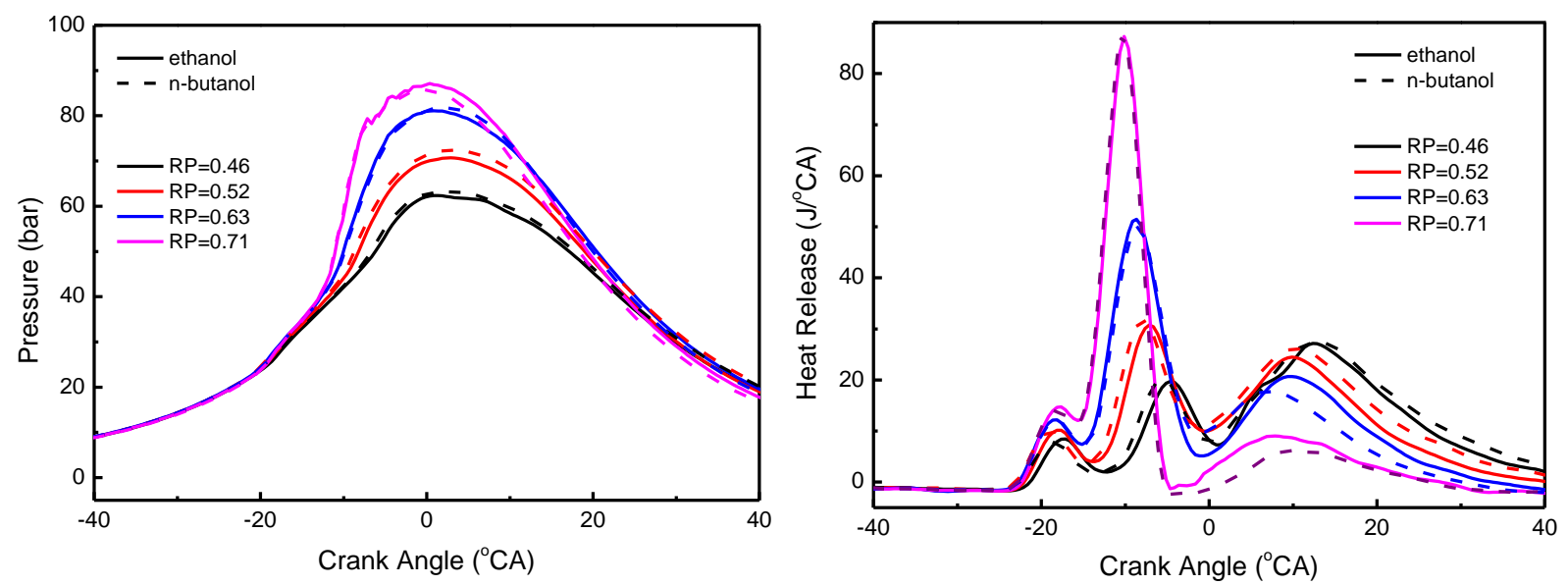

Fig. 2 Effects of the premixed ratio on the in-cylinder gas pressure and the heat release rate curves for the DFSC mode with directly injected fuels 

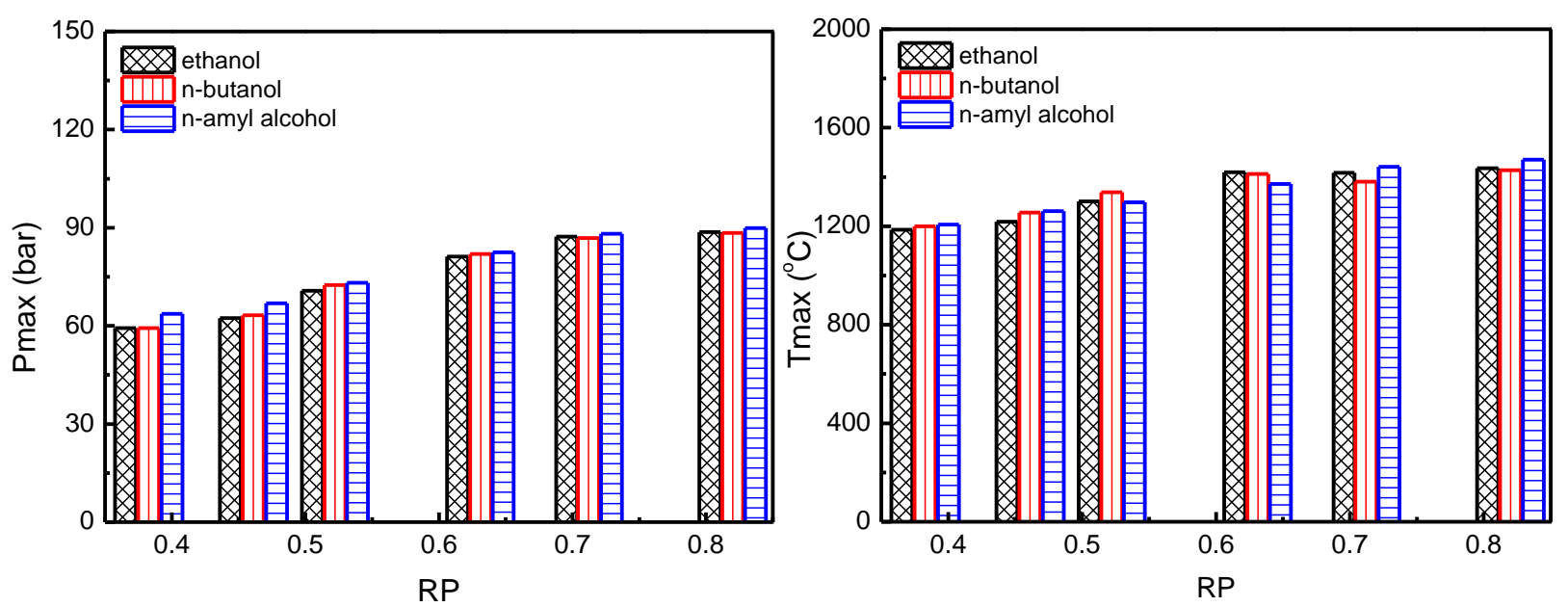

Fig. 3 Effects of the premixed ratio on the in-cylinder Pmax and Tmax for the DFSC mode using directly injected fuels 

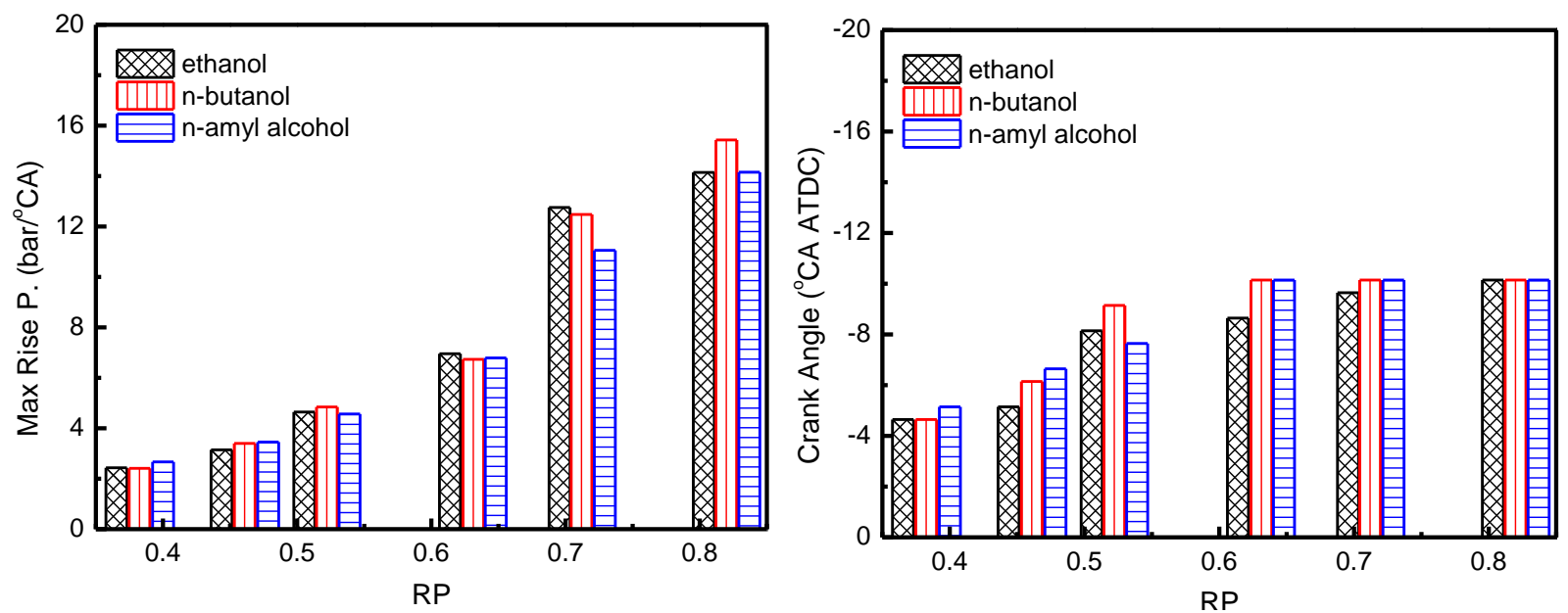

Fig. 4 Effects of the premixed ratio on the maximum pressure rise rate during the DFSC mode with directly injected fuels 

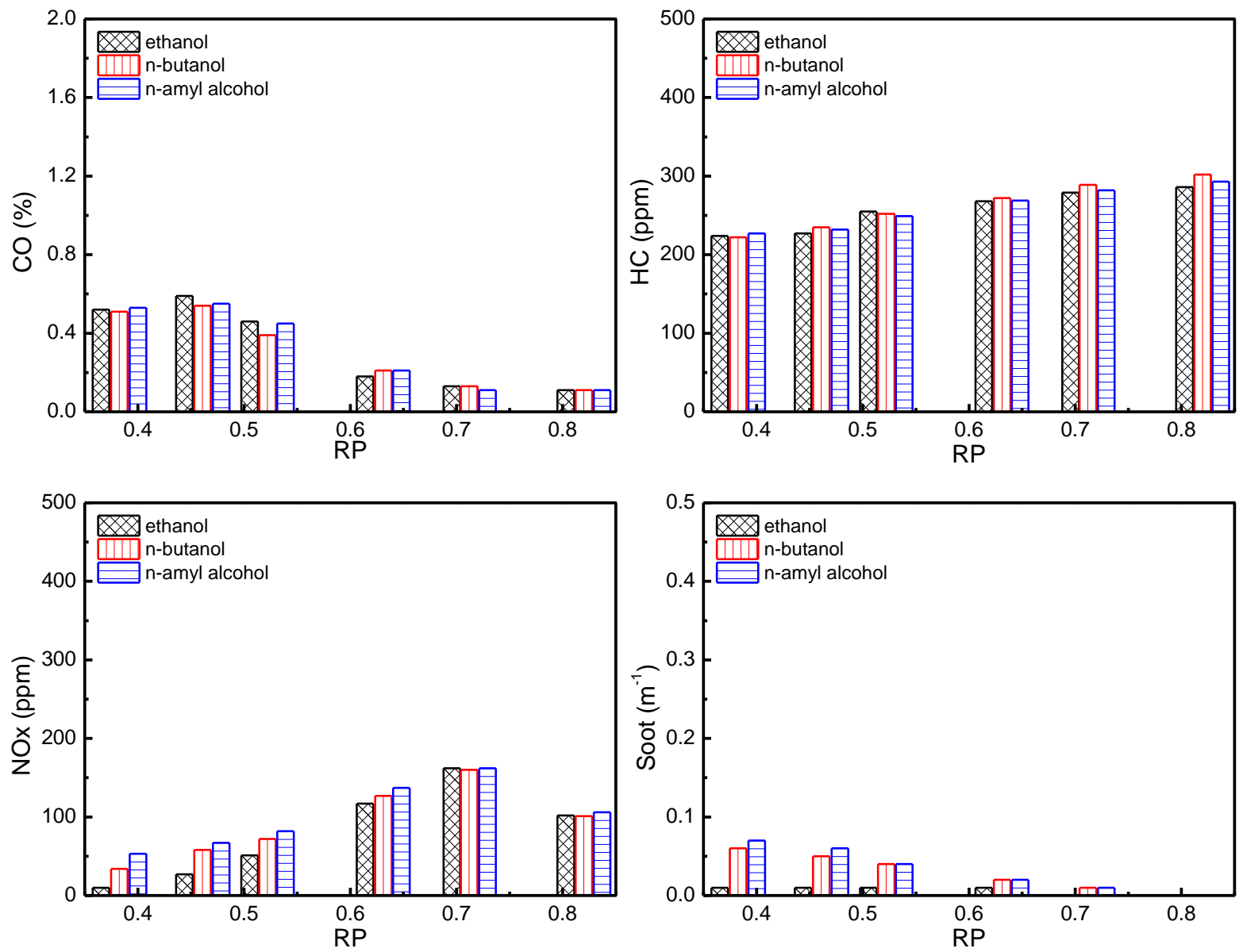

Fig. 5 Effects of the premixed ratio on the emissions of DFSC mode for different directly injected fuels 

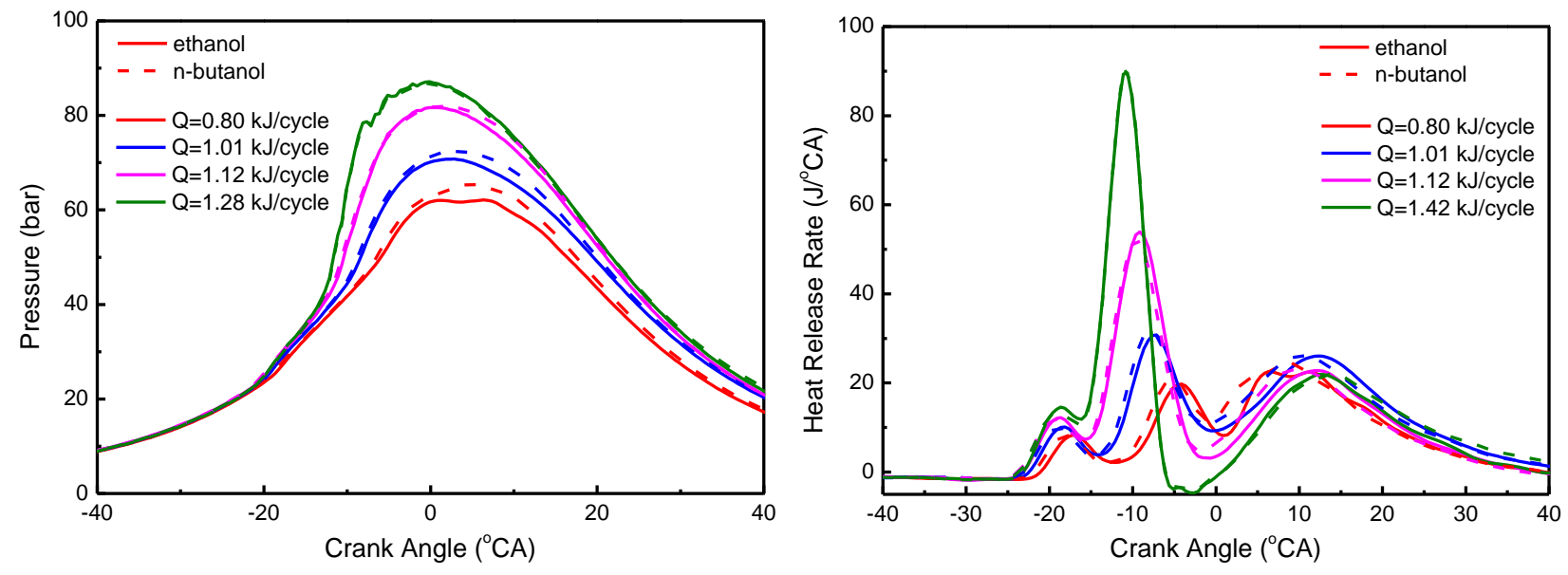

Fig. 6 Effects of the overall LHVs per-cycle on the in-cylinder gas pressure and heat release rate curves for the DFSC mode for different directly injected fuels 

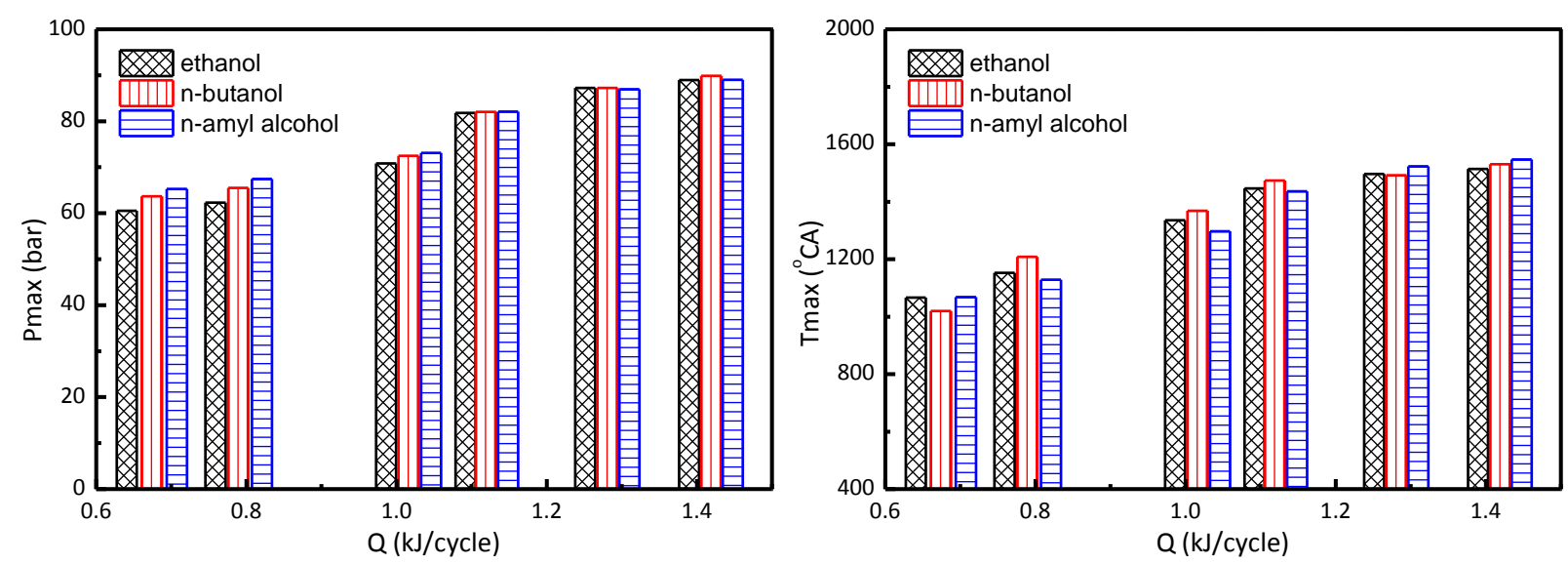

Fig. 7 Effects of the overall LHVs per-cycle on the in-cylinder Pmax and Tmax for the DFSC mode 


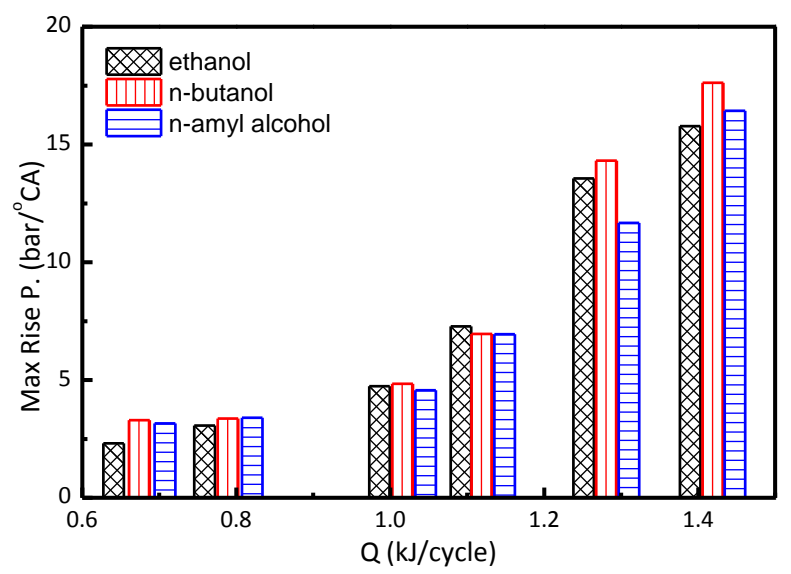

Fig. 8 Effects of the overall LHVs per-cycle on the maximum pressure rise rate for the DFSC combustion mode 


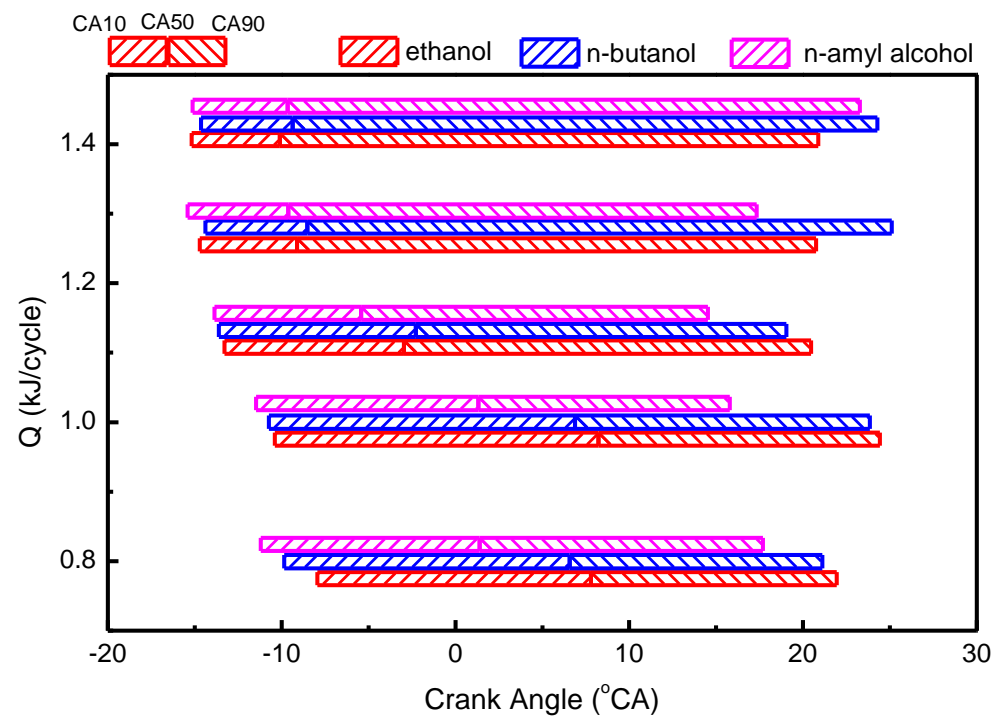

Fig. 9 Effects of the overall LHVs per-cycle on the combustion phase 

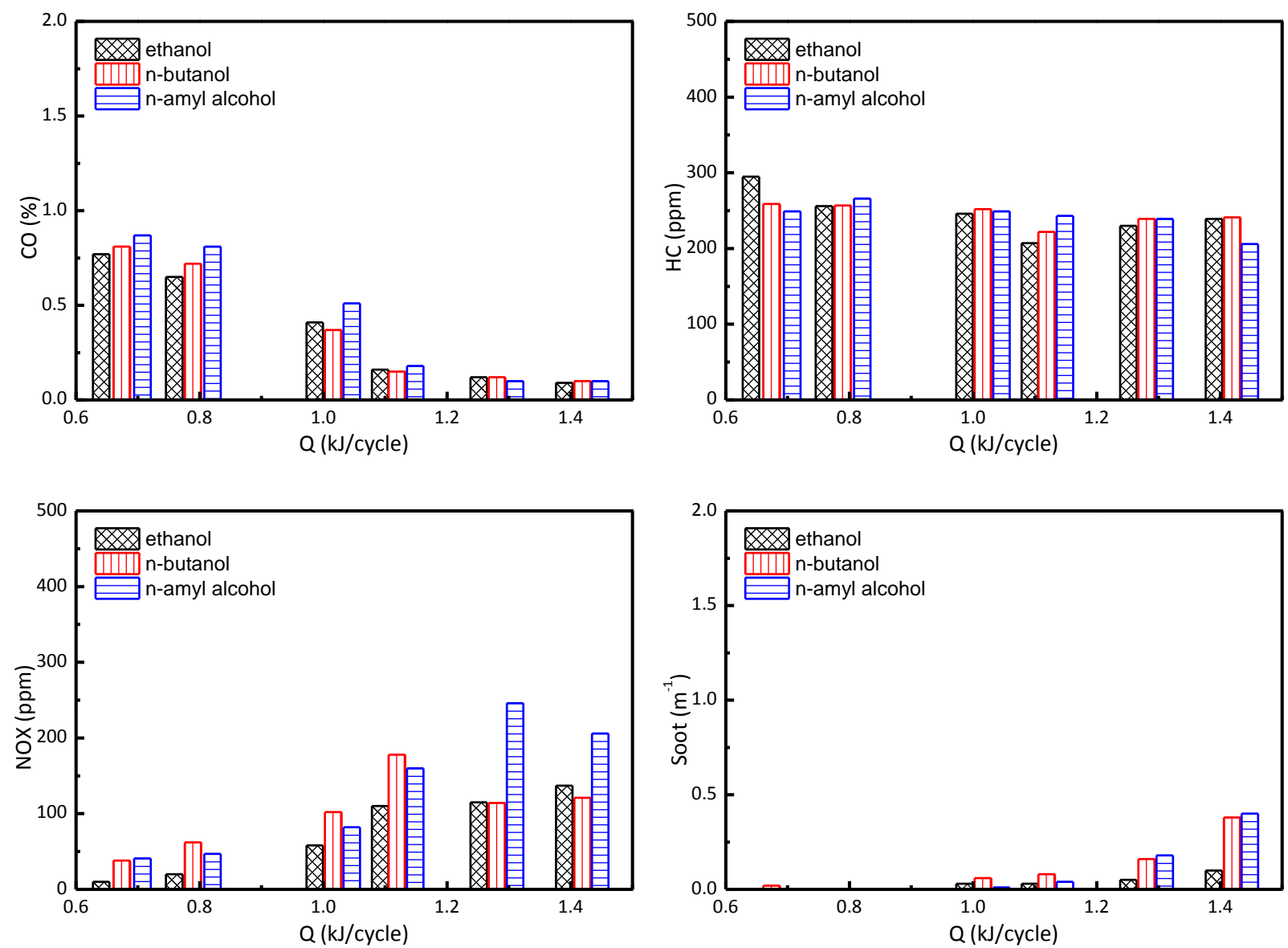

Fig. 10 Effects of overall LHVs per-cycle on the emissions of DFSC combustion mode 


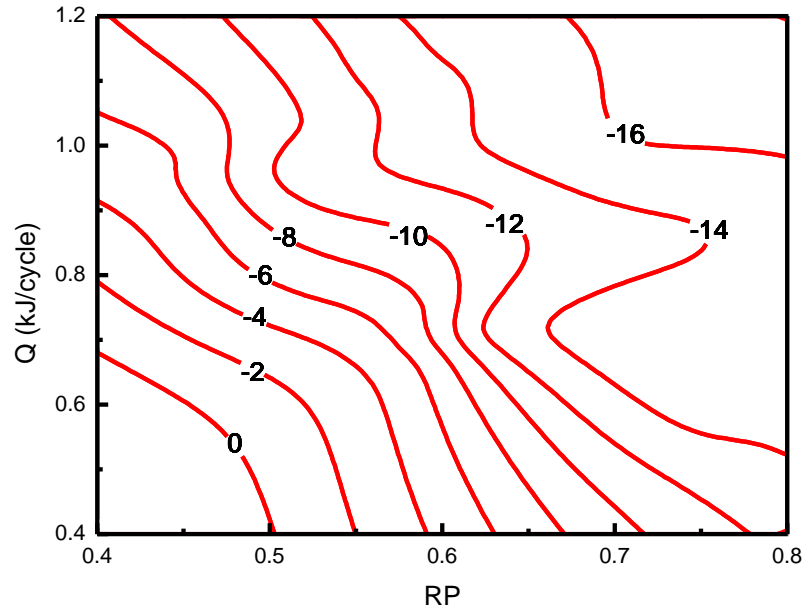

Ethanol

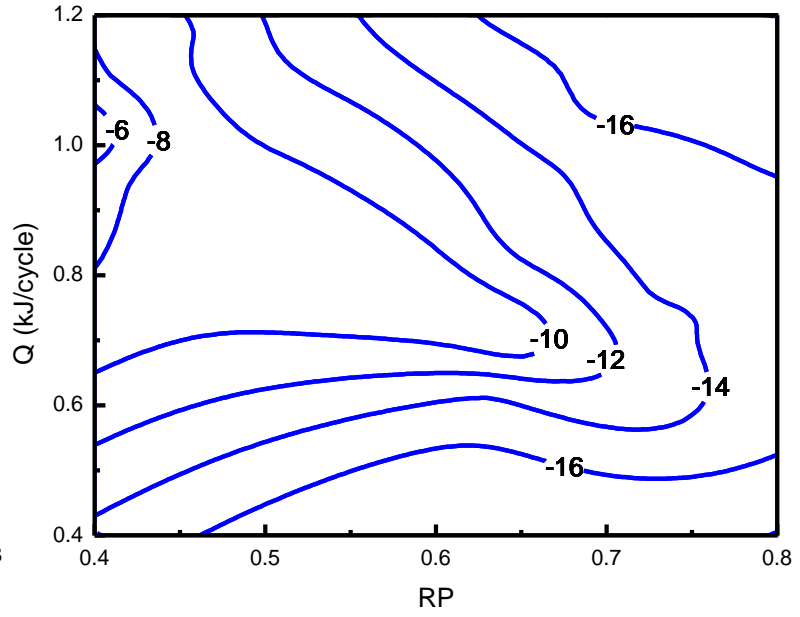

N-butanol

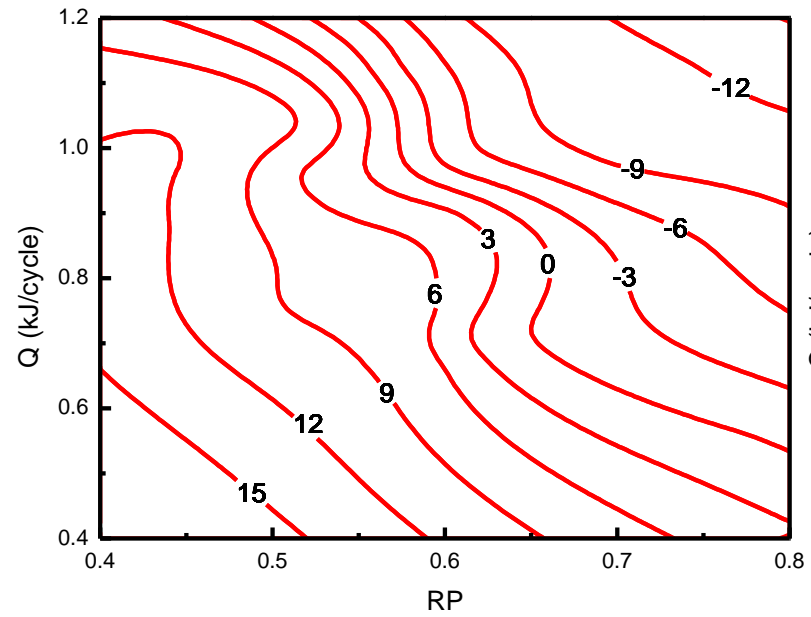

Ethanol

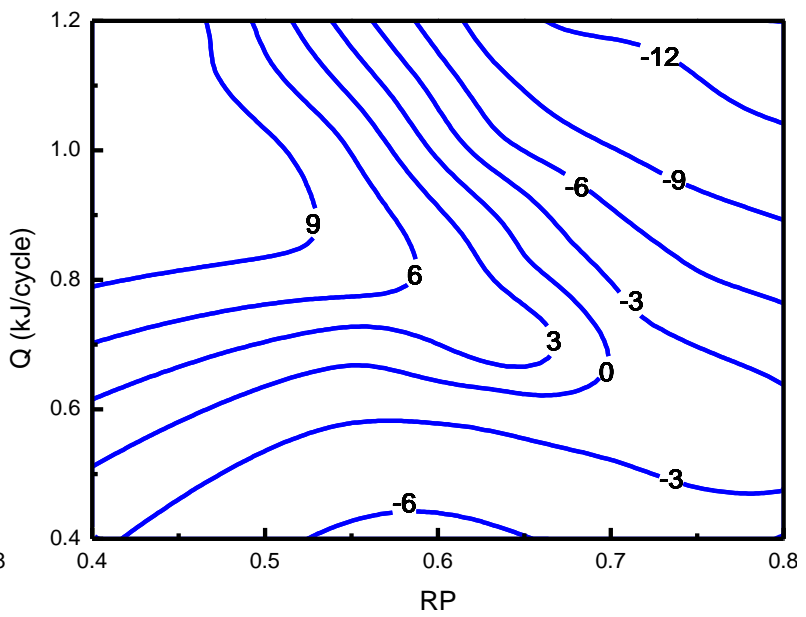

N-butanol

(b) $\mathrm{CA} 50\left({ }^{\circ} \mathrm{CA}\right)$

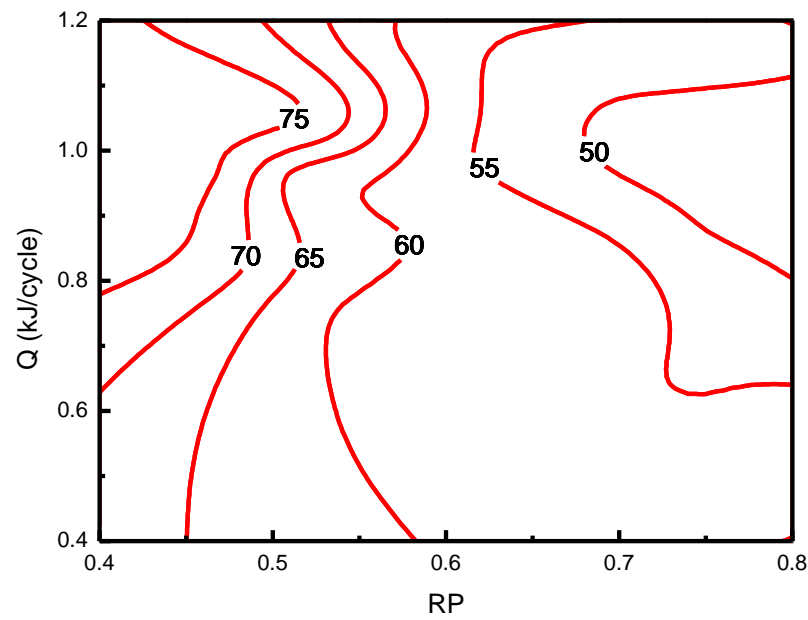

Ethanol

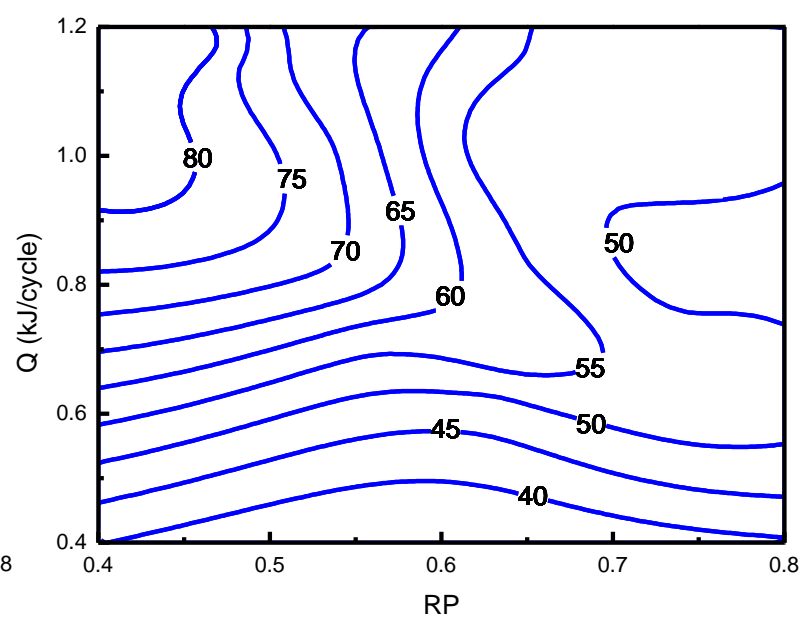

N-butanol

(c) Combustion Duration $\left({ }^{\circ} \mathrm{CA}\right)$

Fig. 11 Combined effects of the premixed ratio and the LHVs per-cycle on the combustion parameters of the DFSC 


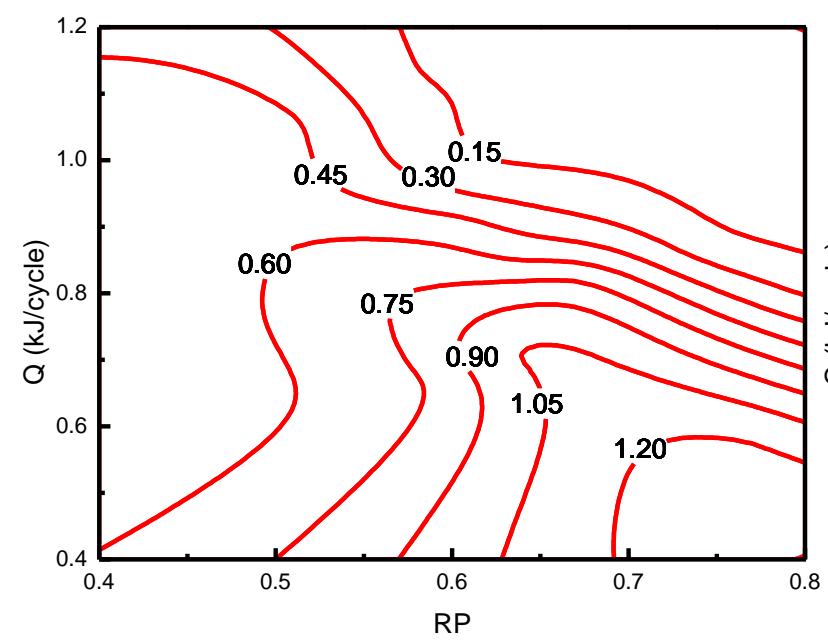

Ethanol

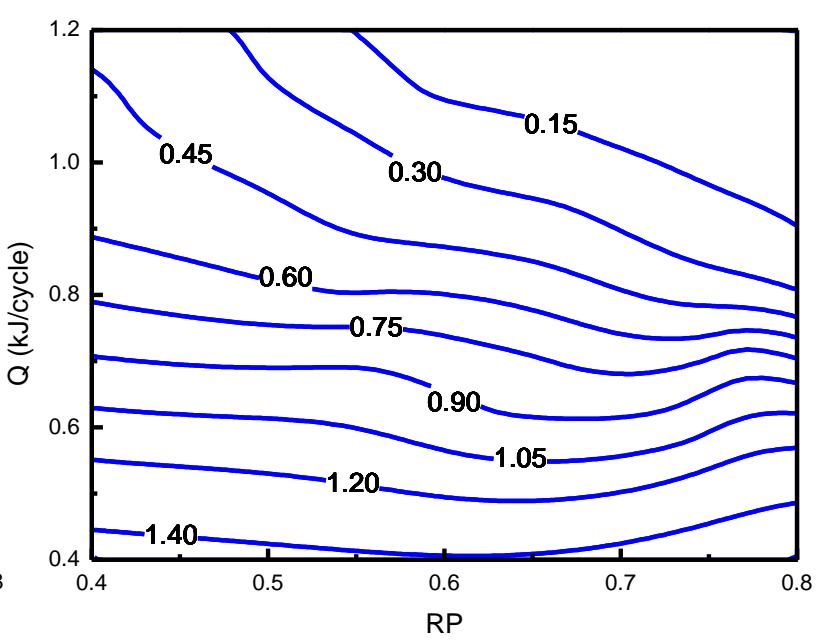

N-butanol

(a) $\mathrm{CO}(\%)$

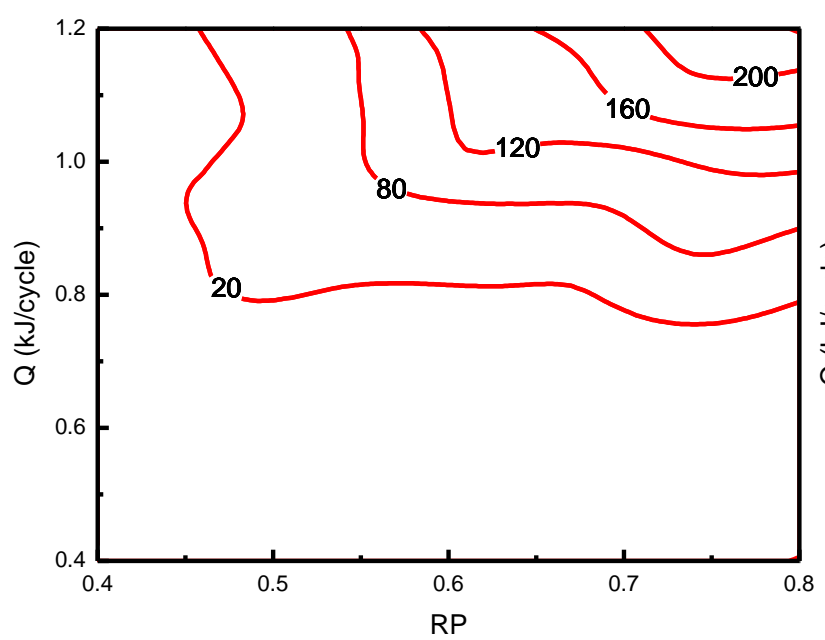

Ethanol

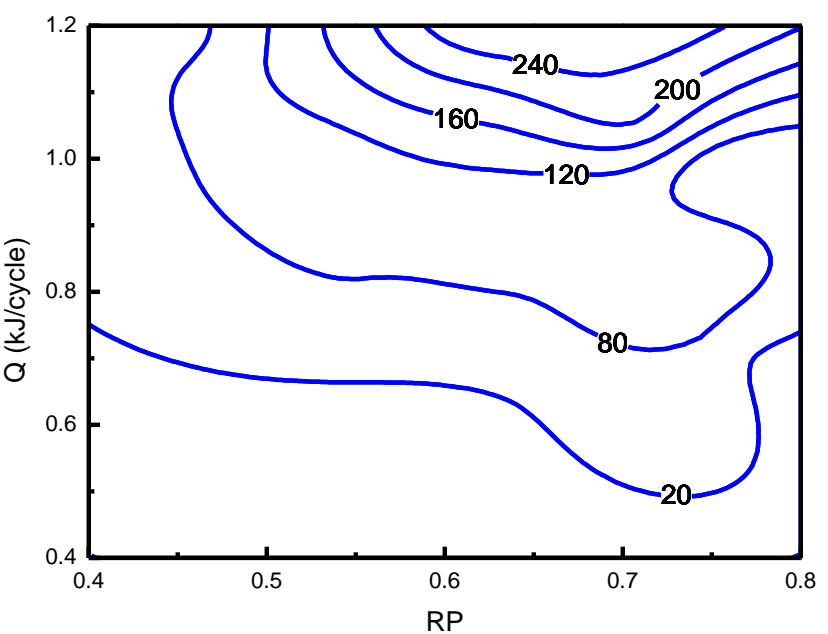

N-butanol

(b) NOx (ppm)

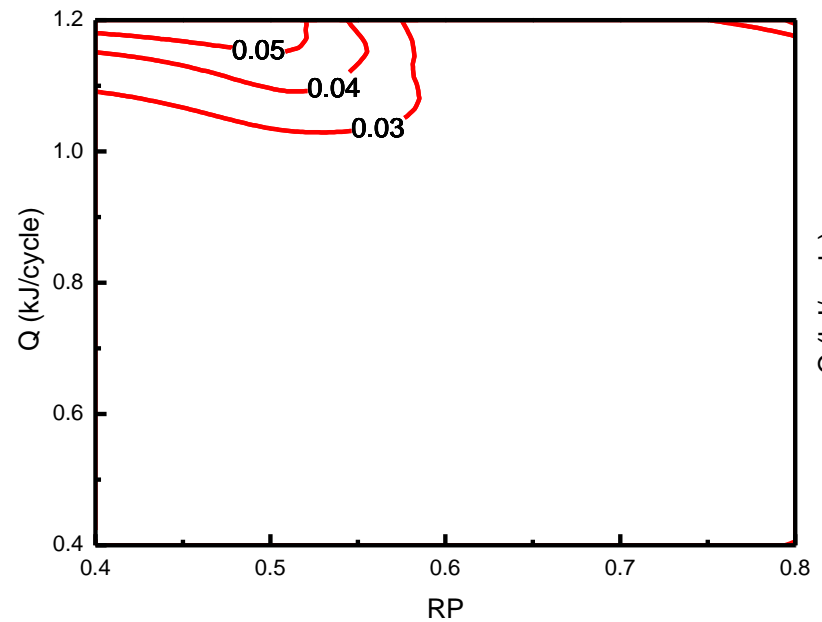

Ethanol

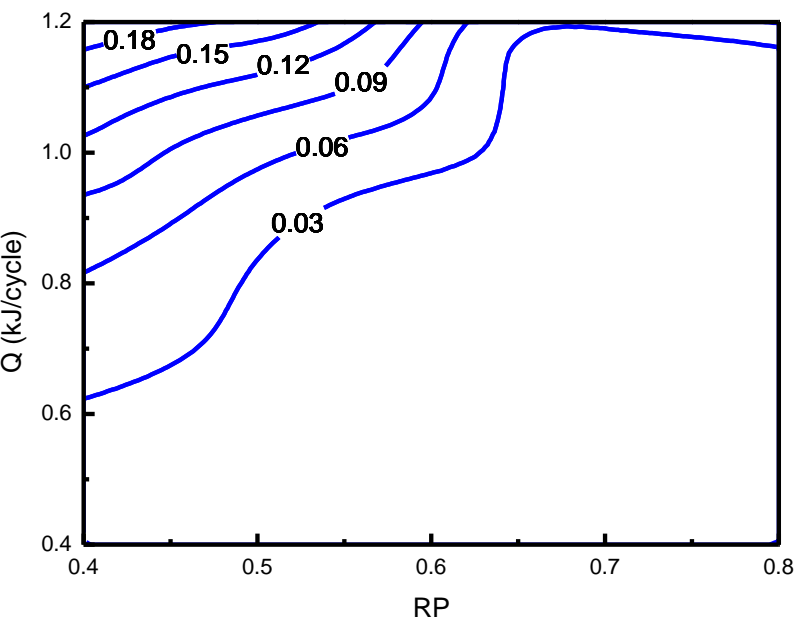

N-butanol

(c) Soot $\left(\mathrm{m}^{-1}\right)$

Fig. 12 Combined effects of the premixed ratio and the LHVs per-cycle on the main gas emissions for the DFSC 


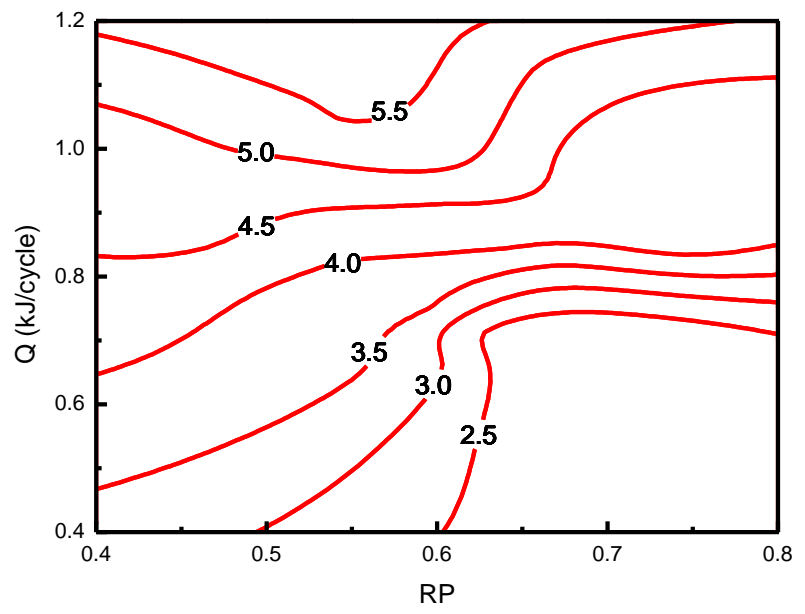

Ethanol

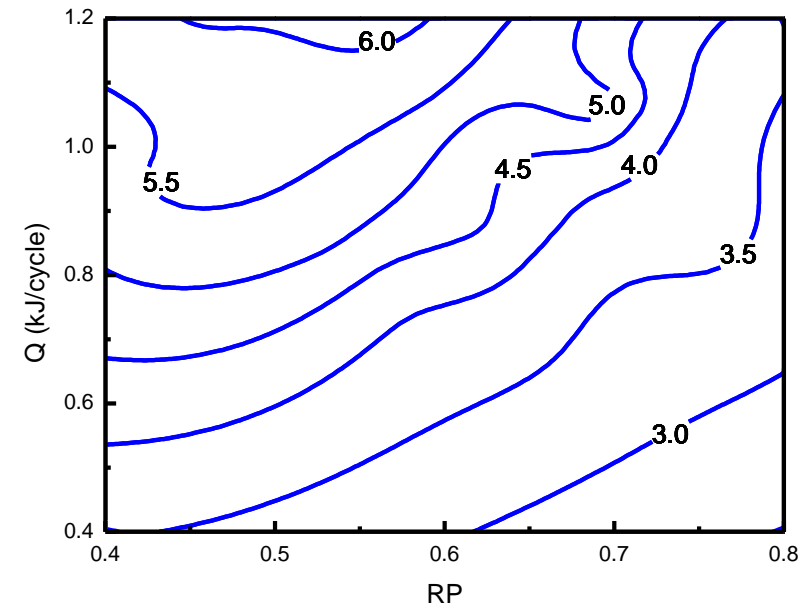

N-butanol

(a) IMEP (bar)

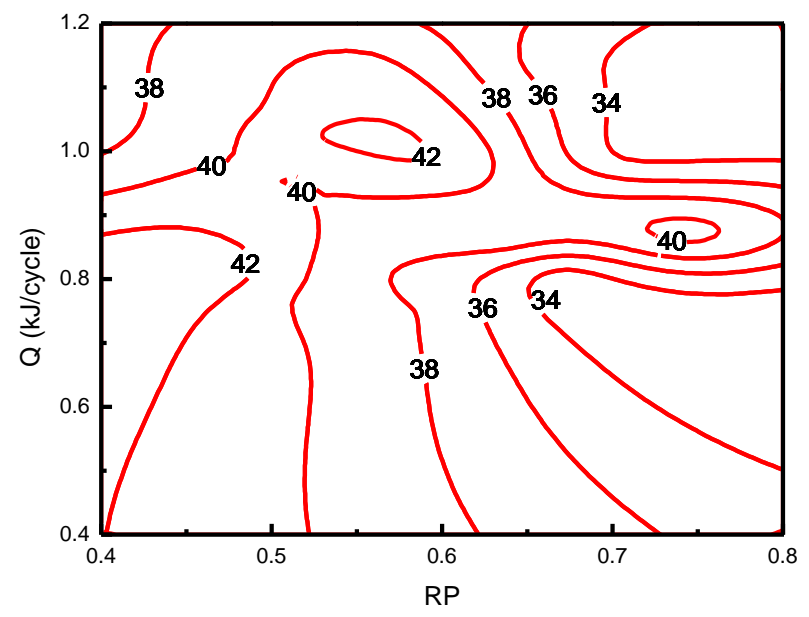

Ethanol

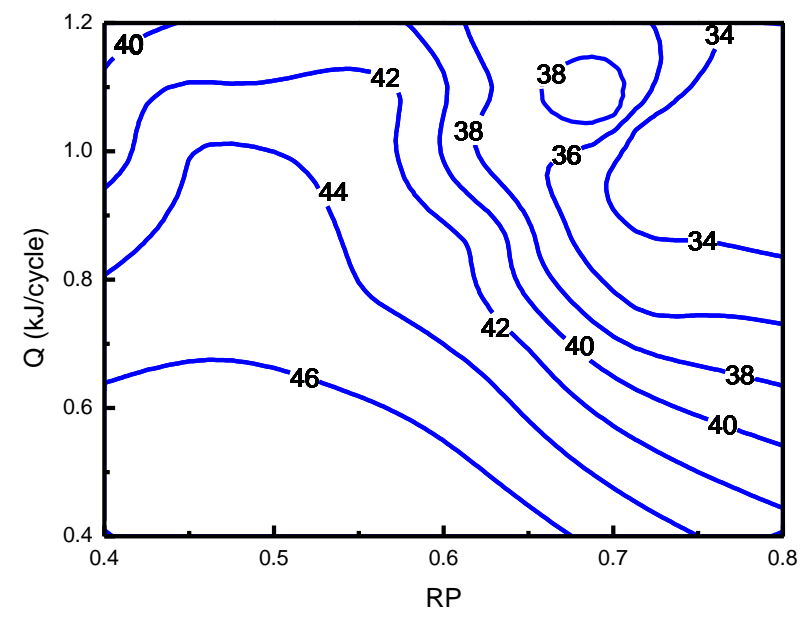

N-butanol

(b) Indicated Thermal Efficiency (\%)

Fig. 13 Combined effects of the premixed ratio and the LHVs per-cycle on the IMEP and indicated thermal efficiency of DFSC mode 